\title{
Lift-Off Assisted Patterning of Few Layers Graphene
}

\author{
Alessio Verna ${ }^{1, *(\mathbb{D})}$, Simone Luigi Marasso $\left.{ }^{1,2} \mathbb{(}\right)$, Paola Rivolo ${ }^{1}$, Matteo Parmeggiani ${ }^{1,3}$, \\ Marco Laurenti ${ }^{1}$ iD and Matteo Cocuzza ${ }^{1,2}$ (D) \\ 1 Chilab-Materials and Microsystems Laboratory, DISAT, Politecnico di Torino-Via Lungo Piazza d'Armi 6 , \\ IT 10034 Chivasso (Torino), Italy; simone.marasso@polito.it (S.L.M.); paola.rivolo@polito.it (P.R.); \\ matteo.parmeggiani@polito.it (M.P.); marco.laurenti@polito.it (M.L.); matteo.cocuzza@infm.polito.it (M.C.) \\ 2 CNR-IMEM, Parco Area delle Scienze 37a, IT 43124 Parma, Italy \\ 3 Center for Sustainable Future Technologies, Italian Institute of Technology, Via Livorno 60, \\ IT 10144 Torino, Italy \\ * Correspondence: alessio.verna@polito.it; Tel.: +39-011-9114899
}

Received: 29 May 2019; Accepted: 21 June 2019; Published: 25 June 2019

\begin{abstract}
Graphene and 2D materials have been exploited in a growing number of applications and the quality of the deposited layer has been found to be a critical issue for the functionality of the developed devices. Particularly, Chemical Vapor Deposition (CVD) of high quality graphene should be preserved without defects also in the subsequent processes of transferring and patterning. In this work, a lift-off assisted patterning process of Few Layer Graphene (FLG) has been developed to obtain a significant simplification of the whole transferring method and a conformal growth on micrometre size features. The process is based on the lift-off of the catalyst seed layer prior to the FLG deposition. Starting from a $\mathrm{SiO}_{2}$ finished Silicon substrate, a photolithographic step has been carried out to define the micro patterns, then an evaporation of $\mathrm{Pt}$ thin film on $\mathrm{Al}_{2} \mathrm{O}_{3}$ adhesion layer has been performed. Subsequently, the $\mathrm{Pt} / \mathrm{Al}_{2} \mathrm{O}_{3}$ lift-off step has been attained using a dimethyl sulfoxide (DMSO) bath. The FLG was grown directly on the patterned Pt seed layer by Chemical Vapor Deposition (CVD). Raman spectroscopy was applied on the patterned area in order to investigate the quality of the obtained graphene. Following the novel lift-off assisted patterning technique a minimization of the de-wetting phenomenon for temperatures up to $1000^{\circ} \mathrm{C}$ was achieved and micropatterns, down to $10 \mu \mathrm{m}$, were easily covered with a high quality FLG.
\end{abstract}

Keywords: graphene; patterning; Pt; 2D materials; chemical vapor deposition (CVD)

\section{Introduction}

In the last years, Single Layer or Few Layer Graphene (SLG-FLG) have been widely exploited to obtain novel high performance devices for different types of applications from electronics [1] to energy storage [2], sensors [3], biomedical implants [4] and others [5,6]. The quality of the SLG or FLG has been found to be a critical issue for the functionality of the devices and hence it is fundamental to improve the production and synthesis steps to avoid defects. To develop an SLG and FLG based device, the typical technological processes involved are: Chemical Vapor Deposition (CVD) on metal catalyst seed layers such as $\mathrm{Cu}$ or $\mathrm{Ni}$ foils [6]; the transferring step on polymer,- - that is, poly(methyl methacrylate) (PMMA) - by spin coating and wet etching; the deposition on active regions, that is, metallic electrodes on $\mathrm{SiO}_{2}$ finished $\mathrm{Si}$ substrates; and finally, the patterning step by plasma etching, laser ablation or other techniques [7]. The transfer of graphene onto arbitrary substrates is generally accomplished by polymer-assisted procedures. The transfer process consists of removing graphene from the growing substrate with the aid of a sacrificial polymer layer. For this purpose, several polymers like poly(methyl methacrylate) and polyvinylidene fluoride (PVDF) are widely employed as sacrificial supports $[7,8]$. Removing of the growing catalyst substrate is accomplished by chemical 
etching [9] or by electrochemical delamination (ED) [10]. Finally, the graphene/polymer self-standing membrane is attached on the target substrate and the polymer is then removed with a suitable solvent [8]. Despite being widely used, this approach may lead to the formation of undesirable defects and damages within the graphene layer. Hence, a major challenge is to minimize such defects by contact transfer processes at wafer scale [11]. As an alternative, the direct growth of graphene on insulating substrates using $\mathrm{Cu}$ vapor [12] or ultrathin $\mathrm{Cu}[13,14]$ and $\mathrm{Ni}[15]$ films as catalyst has been attempted; however, these methods do not allow for a precise control of the defects. Another interesting approach is to pattern the graphene directly on $\mathrm{Cu}$ substrates before transfer [16] ensuring a precise reproduction of the pattern but involving time consuming polymer transfer. Due to the difficulties to grow graphene directly on $\mathrm{Cu}$ or $\mathrm{Ni}$ thin films and due to the incompatibility of these metals in most biological/electrochemical applications, usually graphene is transferred on $\mathrm{Au}$ or $\mathrm{Pt}$ electrodes exploiting the previously described methods.

Several applications require the use of Pt electrodes coated with graphene. These include atomic force microscope (AFM) tips for nanoscale electrical characterization [17], friction reduction in Micro Electro Mechanical System (MEMS) [18], counter electrodes for dye-sensitized solar cells [19], microelectrodes for neurostimulation [20], amperometric sensors in electrophoresis devices [21], electrodes for the electrochemical adsorption of dyes by cyclic voltammetry [22] and electrodes decorated with Pt nanoparticles for electrochemical applications [23,24]. Furthermore, graphene patterning on this type of electrodes is crucial to define the active area of graphene on devices like sensors $[3,25,26]$. This step introduces further defects and damages on the edges [27] or needs for additional technological processes [28].

Due to the high melting point $\left(\mathrm{T}_{\mathrm{m}}=1768^{\circ} \mathrm{C}\right)$ and low vapor pressure $\left(1.3 \times 10^{-14} \mathrm{mmHg}\right), \mathrm{Pt}$ is a well-known catalyst for growing graphene by CVD [29]. In fact, it has been demonstrated that sputtered $\mathrm{Pt}$ thin films do not suffer from de-wetting issues, typical of $\mathrm{Cu}$ and $\mathrm{Ni}$, during monolayer or few layers graphene growth [30]. The stability of Pt thin films against de-wetting [31] phenomena at high temperature on $\mathrm{Si} / \mathrm{SiO}_{2}$ wafers can be also tuned and improved by increasing the thickness of the film [30]. In addition, the use of adhesion layers may lead to similar results with thinner films as well as e-beam evaporated films. Usual adhesion layers for Pt are metals like Ti, Ta or Cr. However, their exposure to high temperatures causes inter-diffusion or oxide formation and their subsequent degradation [32]. Alumina $\left(\mathrm{Al}_{2} \mathrm{O}_{3}\right)$ is preferred as $\mathrm{Pt}$ adhesion layer in high temperature applications [33] due to its thermal and chemical stability. Moreover, it can be deposited with common techniques such as sputtering or e-beam evaporation [34] and then easily integrated in Pt deposition process. Finally, $\mathrm{Pt}$ is also an optimal choice for electrodes in chemical/biological sensors [35] as well as for high temperature micro-hotplates sensors $[36,37]$ due to its high chemical and temperature stability. Therefore, the direct growth of high quality graphene on patterned $\mathrm{Pt}$ thin films may represent an advantage and simplification of the entire device fabrication process.

Here, the direct growth of CVD FLG on Pt thin film was obtained by a lift-off assisted patterning. $\mathrm{Al}_{2} \mathrm{O}_{3}$ was used as adhesion layer to avoid de-wetting of $\mathrm{Pt}$ film. $\mathrm{FLG}$ was grown on patterned $\mathrm{Al}_{2} \mathrm{O}_{3} / \mathrm{Pt}$ substrates with features down to $10 \mu \mathrm{m}$. The graphene quality on patterned areas was evaluated and compared to the graphene grown on un-patterned film by Raman analysis.

\section{Materials and Methods}

\subsection{Lift-Off Assisted Patterning}

The proposed novel method is based on the lift-off of the catalyst seed layer prior to the FLG deposition (Figure 1). Single side polished, $P$ type, (100) silicon wafers (resistivity $1-10 \Omega \cdot \mathrm{cm}$ ) finished with $1 \mu \mathrm{m}$ thermal oxide (supplied by Si-Mat, Kaufering, Germany) were employed for the patterning process. Two $\mathrm{cm} \times$ two $\mathrm{cm}$ squares samples were used in order to fit into the graphene deposition system, which was the NANOCVD-8G system from Moorfield Nanotechnology Ltd. (Cheshire, UK). Samples were cleaned in an acetone bath, rinsed with isopropyl alcohol and then patterned using 
image reversal photoresist (Microchemicals AZ 5214E, Ulm, Germany) and standard UV (ultraviolet) lithography, through a photomask. The next step was the deposition of $30 \mathrm{~nm} \mathrm{of} \mathrm{Al}_{2} \mathrm{O}_{3}$ (purity 99.99\%) followed by $60 \mathrm{~nm}$ of $\mathrm{Pt}$ (purity 99.99\%) by electron beam evaporation (ULVAC EBX-14D, Chigasaki, Japan) with a deposition rate of $2-3 \AA$ /s, both for $\mathrm{Al}_{2} \mathrm{O}_{3}$ and $\mathrm{Pt}$, in high vacuum $\left(<10^{-5} \mathrm{mTorr}\right)$ and heating the samples at $150{ }^{\circ} \mathrm{C}$ during the deposition process.

After the deposition, the photoresist was stripped with dimethyl sulfoxide (DMSO) at $50{ }^{\circ} \mathrm{C}$ and the samples were rinsed with deionized water (DI) and dried with nitrogen.

(a)

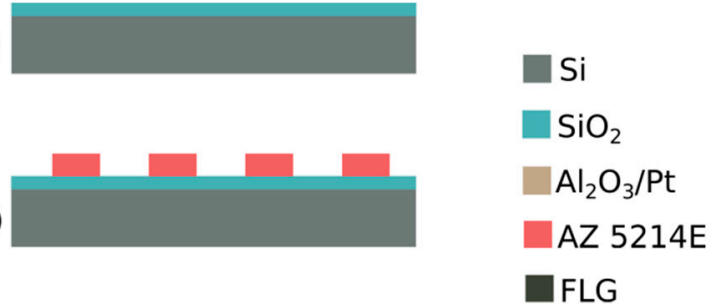

(c)

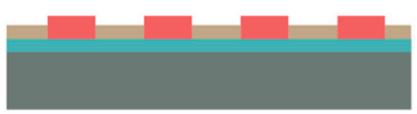

FLG

(d)

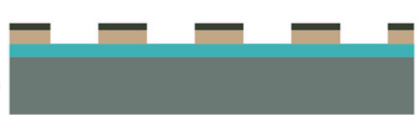

Figure 1. Process flow: (a) starting substrate, (b) photolithography, (c) $\mathrm{Al}_{2} \mathrm{O}_{3} / \mathrm{Pt}$ deposition and lift-off, (d) graphene growth.

\subsection{Graphene Deposition on Pt Film}

Graphene was grown on $\mathrm{Si} / \mathrm{SiO}_{2} / \mathrm{Al}_{2} \mathrm{O}_{3} / \mathrm{Pt}$ substrates by a cold-wall chemical vapor deposition (CVD) reactor operating at low pressure. To remove contaminants from the surface, a two-step annealing of the substrates was performed: $2 \mathrm{~min}$ at $900{ }^{\circ} \mathrm{C}$ under reducing flow of Ar at $190 \mathrm{sccm}$ and $\mathrm{H}_{2}$ at $10 \mathrm{sccm}$ (flow control regime) and then $30 \mathrm{~s}$ at $1000{ }^{\circ} \mathrm{C}$ in an atmosphere composed of $\mathrm{Ar}$ $90 \%$ and $\mathrm{H}_{2} \quad 10 \%$ at 10 torr (pressure control regime). The growth of graphene was then carried out at $1000{ }^{\circ} \mathrm{C}$ for $300 \mathrm{~s}$, in a mixed atmosphere of $\mathrm{Ar}(80 \%), \mathrm{H}_{2}(10 \%)$ and $\mathrm{CH}_{4}(10 \%)$ at 10 torr. The samples were finally cooled down to $200{ }^{\circ} \mathrm{C}$ under a reducing flow of $\mathrm{Ar}+\mathrm{H}_{2}(190 \mathrm{sccm}$ and $10 \mathrm{sccm})$ and then to room temperature in Ar atmosphere.

\subsection{Characterization}

Un-patterned $\mathrm{Al}_{2} \mathrm{O}_{3} / \mathrm{Pt}$ thin films were characterized with field emission scanning electron microscopy (FESEM) after an annealing treatment at $900{ }^{\circ} \mathrm{C}, 1000^{\circ} \mathrm{C}$ and $1050{ }^{\circ} \mathrm{C}$ to investigate the high temperature effect related to the CVD graphene growth process. Images were obtained with FESEM ZEISS Supra 40 (Oberkochen, Germany). For this purpose, the annealing was performed in the same atmosphere and time duration previously described for the growth of graphene but excluding $\mathrm{CH}_{4}$ in the gas mixture.

X-Ray Diffraction (XRD) was performed on un-patterned $\mathrm{Si} / \mathrm{SiO}_{2} / \mathrm{Al}_{2} \mathrm{O}_{3} / \mathrm{Pt}$ substrates with the twofold aim of analysing the corresponding crystal structure and orientation and evaluating the effect of the thermal annealing at $1000{ }^{\circ} \mathrm{C}$. XRD patterns were collected using a Panalytical X'Pert Diffractometer (PANalytical, Almelo, The Netherlands) in Bragg-Brentano configuration, equipped with a Cu K $\alpha$ radiation as X-ray source $(\lambda=1.54059 \AA)$.

Pt/FLG substrates were characterized by means of a Renishaw InVia Reflex micro-Raman spectrometer (Renishaw plc, Wottonunder-Edge, UK), equipped with a cooled CCD camera. The Raman source was a laser diode $(\lambda=514.5 \mathrm{~nm})$ and samples inspection occurred in backscattering light collection through a $50 \times$ microscope objective for all the single spectra acquisition. The spectra of the 
patterned structures were obtained by focusing the laser spot on their centre, while a Raman map of the $10 \mu \mathrm{m}$-wide circle was collected by scanning, by means of a long working distance $100 \times$ objective, a $16 \mu \mathrm{m} \times 16 \mu \mathrm{m}$ area, with a $0.5 \mu \mathrm{m}$ step. The spectral map analysis was performed by means of the Renishaw WiRE 3.2 software. To collect both the single spectra and the map, $50 \mathrm{~mW}$ laser power, $60 \mathrm{~s}$ of exposure time and 4 accumulations were employed.

Optical images were acquired with a Nikon Eclipse ME600 microscope (Nikon, Tokyo, Japan).

\section{Results}

Lift-off assisted patterning of FLG has been successfully obtained (Figure 2) on $\mathrm{Al}_{2} \mathrm{O}_{3} / \mathrm{Pt}$ catalyst film.

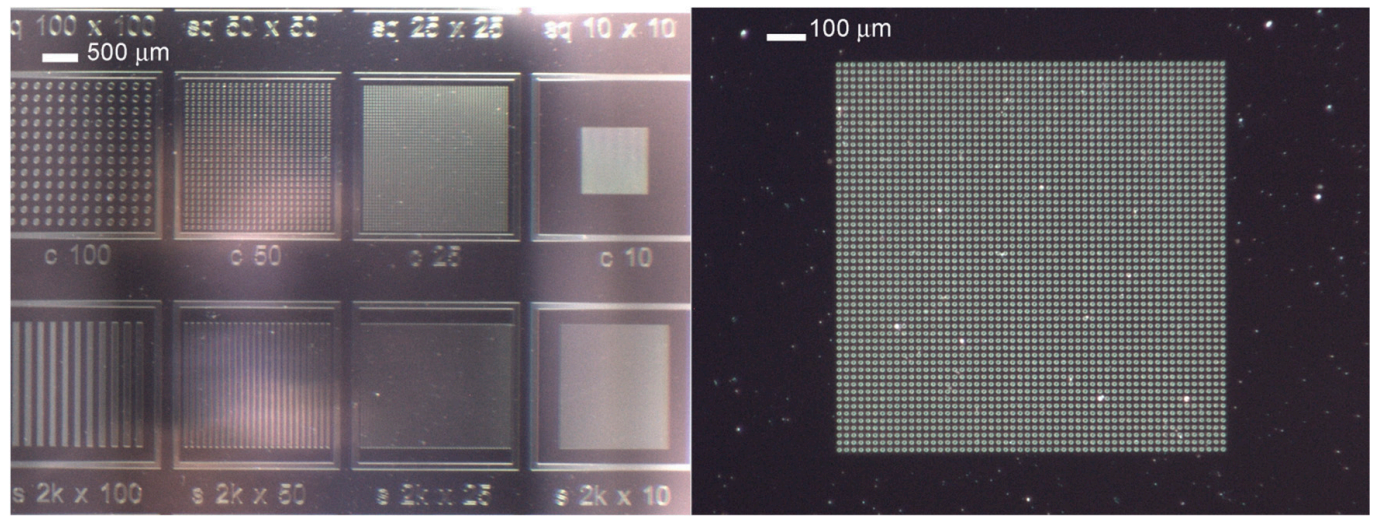

Figure 2. Lift-off assisted patterning of few layers graphene (FLG) on $\mathrm{Pt} / \mathrm{Al}_{2} \mathrm{O}_{3}$ catalyst: optical images of the patterned catalyst with different sizes features.

\subsection{Morphologica Characterization of De-Wetting Dynamic}

The temperature effects were evaluated by thermal annealing tests on $\mathrm{Al}_{2} \mathrm{O}_{3} / \mathrm{Pt}$ layer at $900{ }^{\circ} \mathrm{C}$, $1000^{\circ} \mathrm{C}$ and $1050^{\circ} \mathrm{C}$ (Figure 3 ).

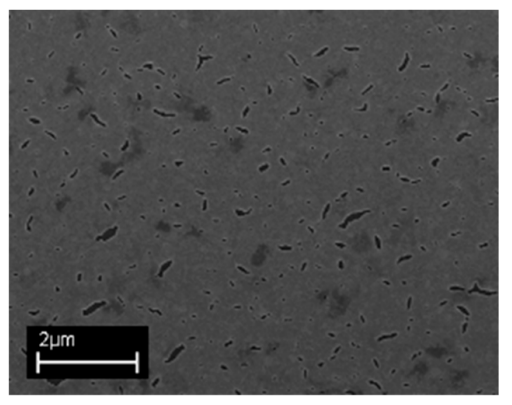

(a)

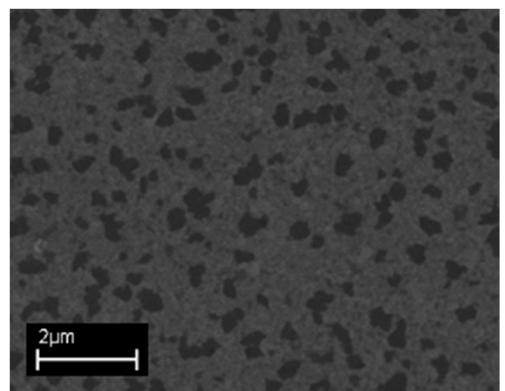

(b)

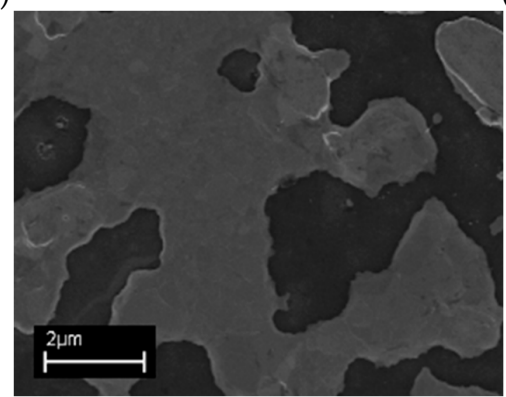

(c)

Figure 3. Comparison of field emission scanning electron microscope (FESEM) images of $\mathrm{Pt} / \mathrm{Al}_{2} \mathrm{O}_{3}$ annealed at $900{ }^{\circ} \mathrm{C}(\mathbf{a}), 1000{ }^{\circ} \mathrm{C}(\mathbf{b})$ and $1050{ }^{\circ} \mathrm{C}$ (c). The film becomes highly discontinuous at $1050{ }^{\circ} \mathrm{C}$ although de-wetting process starts below $900^{\circ} \mathrm{C}$. 
FESEM images demonstrate that the $\mathrm{Al}_{2} \mathrm{O}_{3}$ adhesion layer allows for controlling the de-wetting process (see supplementary information) to achieve a FLG growth temperature up to $1000{ }^{\circ} \mathrm{C}$. It can be noticed that a detrimental effect appears at $1050{ }^{\circ} \mathrm{C}$, where a discontinuous film is formed, making it impractical to use for most technological applications.

\subsection{XRD Characterization}

The diffraction spectrum obtained by XRD investigation (Figure 4) shows a comparison between as-grown $\mathrm{Al}_{2} \mathrm{O}_{3} / \mathrm{Pt}$ samples and the $1000{ }^{\circ} \mathrm{C}$ annealed one. Apart from the contribution coming from the Si substrate $\left(2 \theta-69.2^{\circ}\right)$, a single diffraction peak is detected at $40.1^{\circ}$ in both cases and ascribed to the family of $\mathrm{Pt}(111)$ crystal planes (JCPDS Card 04-0802). After annealing, the crystal quality of the Pt layers turns out to be improved, as demonstrated by the higher $\mathrm{Pt}(111)$ peak intensity. Moreover, the (111) crystal orientation is also highly desirable for promoting graphene growth [23]. This characterization validates $\mathrm{Al}_{2} \mathrm{O}_{3}$ as adhesion layer for this kind of application; indeed, with respect to previous work on a similar process [31], $\mathrm{Al}_{2} \mathrm{O}_{3}$ prevents a premature de-wetting for e-beam evaporated Pt film.

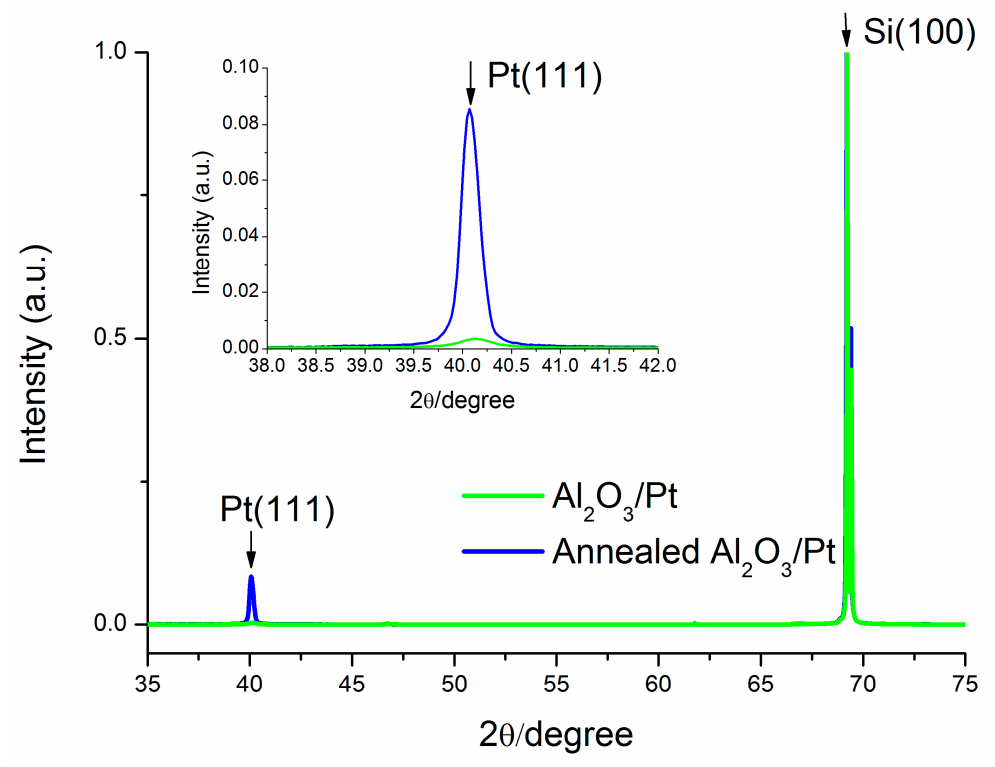

Figure 4. X-ray diffraction (XRD) patterns of $\mathrm{Al}_{2} \mathrm{O}_{3} / \mathrm{Pt}$ samples, before and after annealing at $1000{ }^{\circ} \mathrm{C}$. Annealed sample shows the amplification of $\mathrm{Pt}(111)$ phase which is suitable for graphene growth. The inset shows a magnification of the $\mathrm{Pt}(111)$ phase.

\subsection{Raman Characterization of Patterned Pt}

The patterned $\mathrm{Al}_{2} \mathrm{O}_{3} / \mathrm{Pt}$ was characterized by Raman spectroscopy to evaluate the quality of the grown graphene, which according to Wang et al. was about 2-3 layers [38].

The analysis was performed with the aim to evaluate the selective growth of FLG on Pt patterns with respect to $\mathrm{SiO}_{2}$ and the correlation between the FLG defectivity and the patterns sizes. Furthermore, growing temperature effect was investigated. Raman spectra of FLG on both un-patterned (red curve) and patterned Pt samples ranging from 5 to $100 \mu \mathrm{m}$ wide strips were reported (Figure 5). For the patterned Pt samples, the Raman spectra were collected on a 1-2 $\mu$ m wide area, far from the edges. The intensity (I), position and shape of D, G and 2D peaks (centred at $\sim 1350,1580$ and $2700 \mathrm{~cm}^{-1}$ respectively) are similar for the $100 \mu \mathrm{m}$ patterned and un-patterned areas but the intensity of the D peak differs on the $5 \mu \mathrm{m}$ pattern. The presence of an ubiquitous peak at $\sim 2324 \mathrm{~cm}^{-1}$ can be related to atmospheric $\mathrm{N}_{2}$ gas fundamental vibration-rotation as previously reported [39].

For the FLG growth on the un-patterned Pt sample, the G peak only differs from the patterned ones in shape and intensity with respect to the $\mathrm{D}$ band: a narrower and more symmetric band and an $\mathrm{I}_{\mathrm{D}} / \mathrm{I}_{\mathrm{G}}$ 
ratio of $\sim 0.20$ are observable. Moreover, the calculated $\mathrm{I}_{\mathrm{D}} / \mathrm{I}_{\mathrm{G}}$ is $\sim 0.31$ on the $100 \mu \mathrm{m}$ pattern and $\sim 0.73$ on the $5 \mu \mathrm{m}$ pattern suggesting that the presence of the microstructures could induce a more disordered superposition of the graphene few layers. As pointed out in the review by Ferrari and Basko [40], other factors confirm the disorder induced in the case of patterned Pt/FLG with respect to plain film; these include: the increased dispersion of the $G$ peak; the small elbow at the right of the $G$ peak which could be associated with a small $\mathrm{D}^{\prime}$ peak and the noise at the left of 2D which could be associated with the $\mathrm{D}^{\prime \prime}$ peak. On the other hand, the shape and position of the 2D band for both samples (un-patterned and patterned) indicate that the number and the quality of the deposited graphene sheets are quite comparable, as the peak, though symmetric, cannot be fitted by one Lorentzian and it has a FWHM of $\sim 77 \mathrm{~cm}^{-1}, 64 \mathrm{~cm}^{-1}$ and $84 \mathrm{~cm}^{-1}$ respectively for un-patterned, $100 \mu \mathrm{m}$ and $5 \mu \mathrm{m}$ patterns, which are compatible with the characteristics of FLG grown on a nickel-coated $\mathrm{SiO}_{2} / \mathrm{Si}$ substrate, previously reported by Park et al. [41].

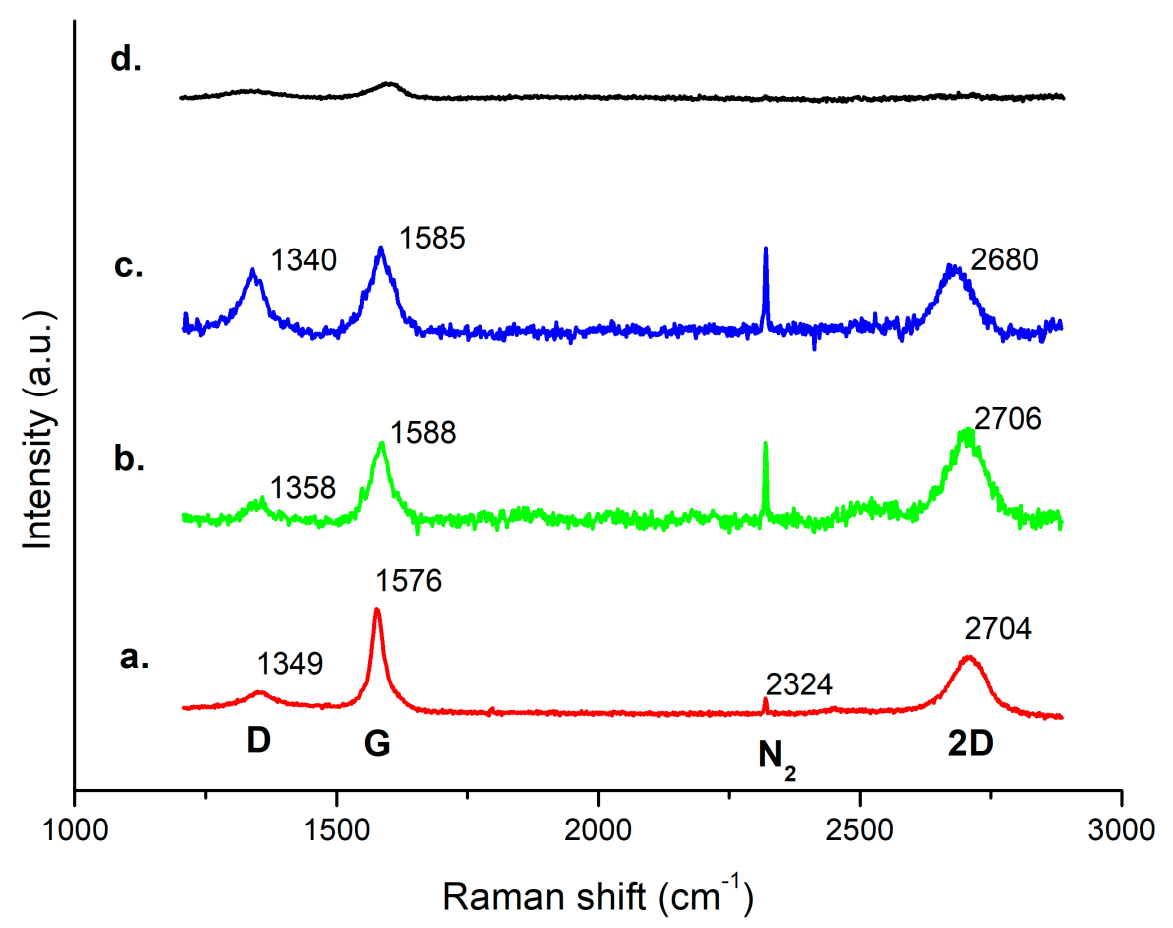

Figure 5. Comparative Raman spectra of un-patterned Pt/FLG (a), $100 \mu \mathrm{m}$ strip pattern (b), $5 \mu \mathrm{m}$ strip pattern (c) and blank silicon collected between two $100 \mu \mathrm{m}$ Pt strips (d). The main peaks labels are shown.

Patterned Pt/FLG grown at $900{ }^{\circ} \mathrm{C}, 1000{ }^{\circ} \mathrm{C}$ and $1050{ }^{\circ} \mathrm{C}$ was further characterized by Raman spectroscopy (Figure 6). It can be noticed that at $1050^{\circ} \mathrm{C}$ graphene quality improves although $\mathrm{Pt}$ thin film undergoes de-wetting effect and, with the increasing temperature, the ratio between 2D and $G$ peaks also increases indicating a reduction in the number of layers. Moreover, both $D$ peak intensity reduction and $\mathrm{G}$ peak sharpness indicate a minimization of the graphene defects. But from the comparison with morphological analysis (Figure 3), at $1050{ }^{\circ} \mathrm{C}$ the de-wetting of the $\mathrm{Pt}$ film has relevant detrimental effect. 


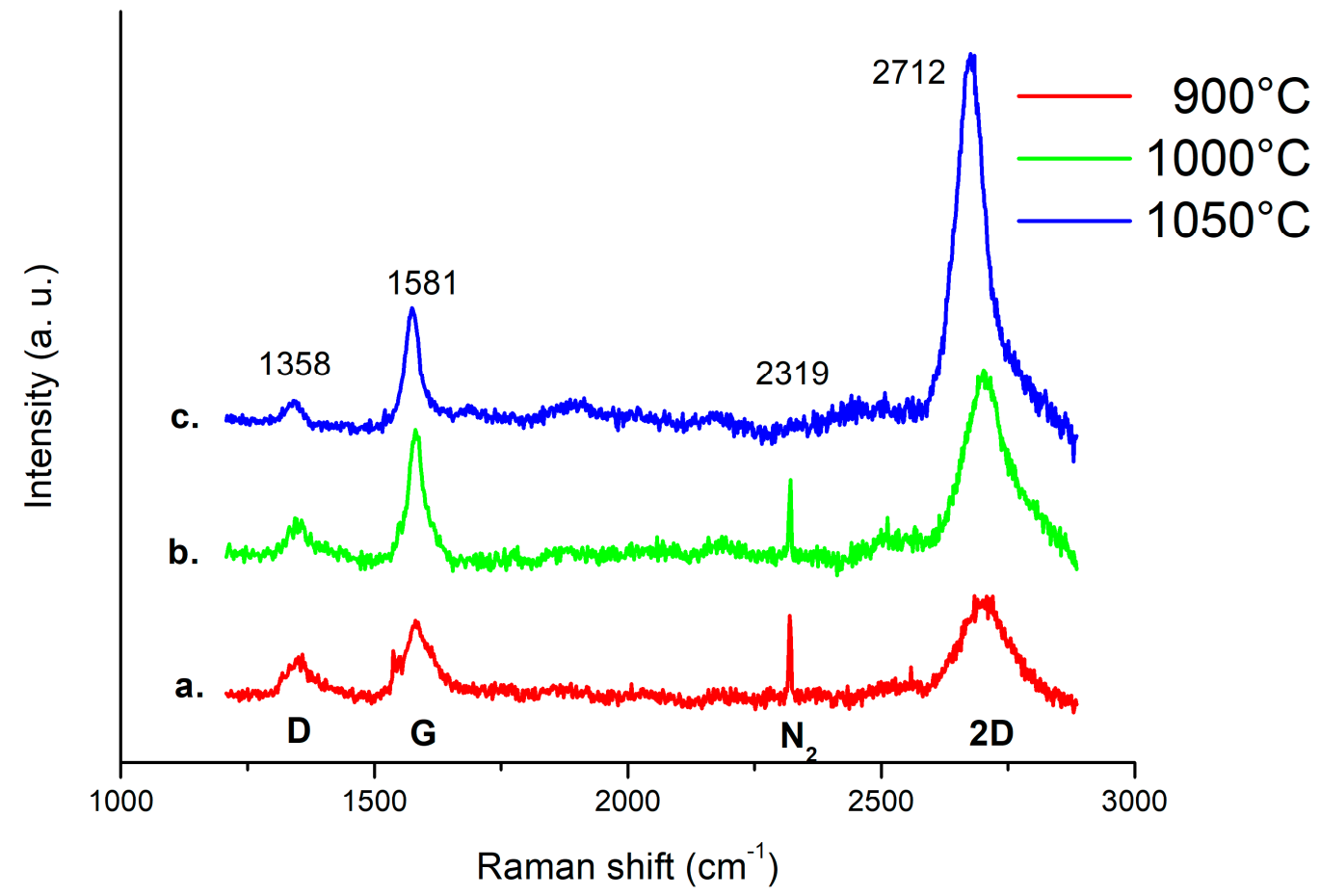

Figure 6. Comparative Raman spectra of $100 \mu \mathrm{m}$ patterns of $\mathrm{Pt} / \mathrm{FLG}$ grown at $900{ }^{\circ} \mathrm{C}(\mathbf{a})$, at $1000{ }^{\circ} \mathrm{C}(\mathbf{b})$ and at $1050{ }^{\circ} \mathrm{C}$ (c). The ratio between $2 \mathrm{D}$ and $\mathrm{G}$ peaks intensities increases indicating a reduction in the number of layers with temperature. The main peaks labels are shown.

Figure 7 shows FLG Raman spectra from the centre of a $5 \mu \mathrm{m}$ strip to the border of the same pattern and then in a region $2.5 \mu \mathrm{m}$ far from the edge. A transition from graphene to graphitic carbon residual is observed as the developing of $\mathrm{D}$ and $\mathrm{G}$ peaks indicate the presence of $\mathrm{sp}^{2}$ carbon with a consistent number of defects as previously reported [42].

In order to verify the homogeneity of the FLG distribution and possible physical boundary effects, the scanning of a $16 \times 16 \mu \mathrm{m}^{2}$ area, including circle-shaped patterns (10 $\mu \mathrm{m}$ in diameter), was performed. The collected spectral Raman map (Figure 8) highlights that, in the inner region of the microstructure, the intensities of the $\mathrm{D}, \mathrm{G}$ and $2 \mathrm{D}$ bands are quite constant in distribution and mutual ratio. Then, all the peak intensities increase by approaching the edge of the micro-circle, suggesting an accumulation of more defective and lower quality graphene sheets within such regions. Beyond the microstructure boundaries, no Raman features related to FLG are present, in accordance with blank spectrum (black curve) of Figure 6. This demonstrates the high selectivity of the growing process. Regarding defects accumulation on the edges, it is possible to assume that the discontinuities on the catalyst can affect the formation of graphene crystal domains thus leading to a more disordered growth. 


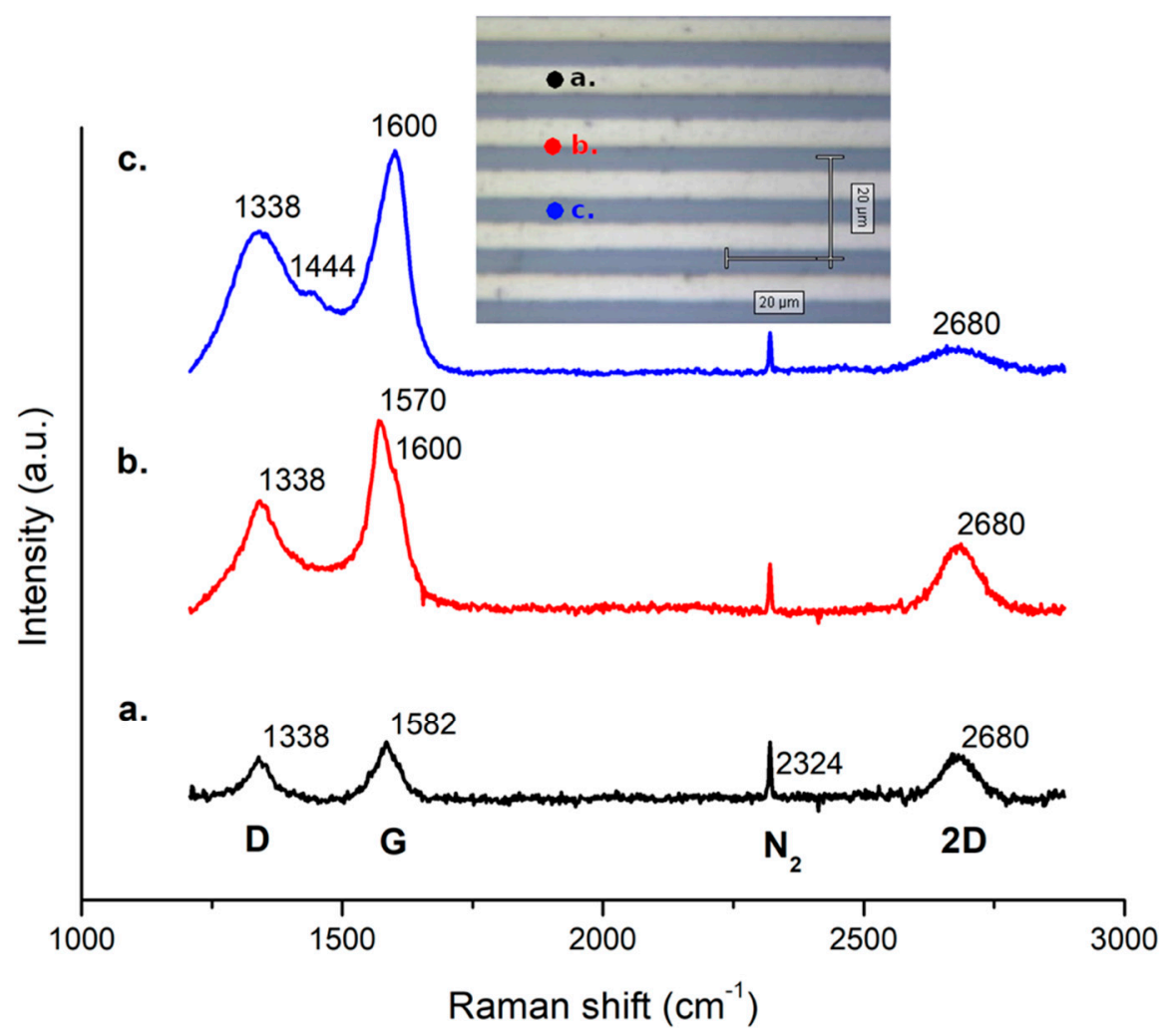

Figure 7. Raman spectra on $5 \mu \mathrm{m}$ wide strips at different positions at the centre of the strip (a), on the border (b) and between two strips (c). The main peaks labels are shown. The inset shows an optical image of the sample. A graphitic carbon residual is observed in (c) while in un-patterned areas (Figure 5d) no carbon residuals are present. This shows that amorphous carbon deposition is catalysed by the presence of platinum also in a halo of 1-2 $\mu \mathrm{m}$ outside the pattern.

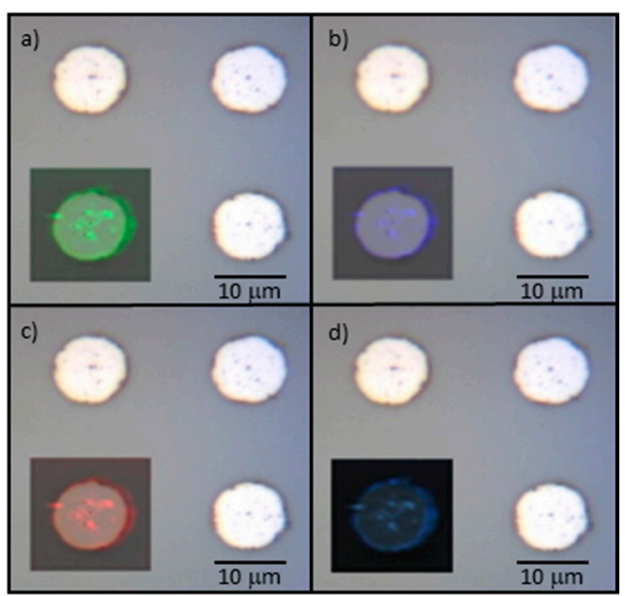

Figure 8. Raman map of a $10 \mu \mathrm{m}$ wide circle. The map is superimposed to the optical image of 4 circles pattern for comparison. Map shows intensities distribution at $1350 \mathrm{~cm}^{-1}(\mathbf{a}), 1580 \mathrm{~cm}^{-1}$ (b), $2700 \mathrm{~cm}^{-1}$ (c), overlap of all the selected Raman shift intensity distributions (d).

\section{Discussion}

The reported analysis demonstrates that the lift-off assisted patterning is a valid method to obtain good quality FLG on Pt layer. A significant time reduction with respect to traditional process was achieved since the typical transferring steps were completely skipped. In addition, this method is not affected by the contamination of supporting polymers as PMMA. The obtained optimal repeatability on micrometric patterns allows for covering $\mathrm{Pt}$ film with every layouts and, more important, $\mathrm{Pt}$ can 
be deposited with common techniques such as sputtering or e-beam evaporation and then easily integrated in a full device fabrication process. Pt represents an optimal metal selection for electrodes in chemical/biological sensors [5] as well as for high temperature micro-hotplates in Micro Electro Mechanical System (MEMS) [6], due to its high chemical and temperature stability and hence the implementation of this method is of high relevance for a wide range of applications from biosensing to neuronal stimulation.

\section{Conclusions}

This FLG was grown directly on the patterned Pt seed layer by Chemical Vapor Deposition (CVD). The use of a proper adhesion layer, $\mathrm{Al}_{2} \mathrm{O}_{3}$, for the $\mathrm{Pt}$ film allows for raising the FLG growth temperature up to $1000^{\circ} \mathrm{C}$. The lift-off process of the catalyst, obtained by a standard photolithographic step, leads to a significant time reduction and consequent costs, of the graphene patterning since the typical transferring and etching steps were completely skipped, moreover an optimal repeatability on micrometric patterns can be easily obtained. The Raman characterization shows that the micropatterning was effective, and an accumulation of defects was mostly observed on the edges due to the discontinuity of the patterns. Since $\mathrm{Pt}$ is one of the most used materials for electrochemical or gas sensors due to its high thermal and chemical stability, the presented patterning approach has a potential high impact on the fabrication of graphene-based devices, when high quality graphene is required on noble metal electrodes. Moreover, the presented process can be applied to fabricate microelectrodes directly decorated with graphene on a whole wafer of any size avoiding the constraints correlated to polymer-assisted graphene transfer and etching.

Supplementary Materials: The following are available online at http://www.mdpi.com/2072-666X/10/6/426/s1, Figure S1: FESEM images at different magnifications of graphene growth on Pt at $900{ }^{\circ} \mathrm{C}$. Figure S2: FESEM images at different magnifications of graphene growth on Pt at $1000^{\circ} \mathrm{C}$. Figure S3: FESEM images at different magnifications of graphene growth on Pt at $1050{ }^{\circ} \mathrm{C}$. Table S1: Percentage of Pt coverage to evaluate de-wetting.

Author Contributions: Conceptualization, A.V.; validation, P.R., M.L.; formal analysis, P.R. and M.P.; investigation, A.V.; writing—original draft preparation, A.V.; writing—review and editing, S.L.M.; supervision, M.C.

Funding: This research received no external funding.

Conflicts of Interest: The authors declare no conflict of interest.

\section{References}

1. Dragoman, M.; Dragoman, D. Graphene-based quantum electronics. Prog. Quantum Electron. 2009, 33, 165-214. [CrossRef]

2. Marasso, S.L.; Rivolo, P.; Giardi, R.; Mombello, D.; Gigot, A.; Serrapede, M.; Benetto, S.; Enrico, A.; Cocuzza, M.; Tresso, E.; et al. A novel graphene based nanocomposite for application in 3D flexible micro-supercapacitors. Mater. Res. Express 2016, 3, 065001. [CrossRef]

3. Hill, E.W.; Vijayaragahvan, A.; Novoselov, K. Graphene sensors. IEEE Sens. J. 2011, 11, 3161-3170. [CrossRef]

4. Podila, R.; Moore, T.; Alexis, F.; Rao, A. Graphene Coatings for Biomedical Implants. J. Vis. Exp. 2013, 73, 1-9. [CrossRef] [PubMed]

5. Zhang, Y.I.; Zhang, L.; Zhou, C. Review of Chemical Vapor Deposition of Graphene and Related Applications. Acc. Chem. Res. 2013, 46, 2329-2339. [CrossRef] [PubMed]

6. Ghorban Shiravizadeh, A.; Elahi, S.M.; Sebt, S.A.; Yousefi, R. High performance of visible-NIR broad spectral photocurrent application of monodisperse PbSe nanocubes decorated on rGO sheets. J. Appl. Phys. 2018, 123, 083102. [CrossRef]

7. Barin, G.B.; Song, Y.; Gimenez, I.D.F.; Filho, A.G.S.; Barreto, L.S.; Kong, J. Optimized graphene transfer: Influence of polymethylmethacrylate (PMMA) layer concentration and baking time on grapheme final performance. Carbon 2015, 84, 82-90. [CrossRef]

8. Song, J.; Kam, F.; Png, R.; Seah, W.; Zhuo, J.; Lim, G.; Ho, P.K.H.; Chua, L. A general method for transferring graphene onto soft surfaces. Nat. Nanotechnol. 2013, 8, 356-362. [CrossRef] 
9. Lee, Y.; Bae, S.; Jang, H.; Jang, S.; Zhu, S.-E.; Sim, S.H.; Song, Y.I.; Hong, B.H.; Ahn, J.-H. Wafer-Scale Synthesis and Transfer of graphene films. Nano Lett. 2010, 10, 490-493. [CrossRef]

10. Gao, L.; Ren, W.; Xu, H.; Jin, L.; Wang, Z.; Ma, T.; Ma, L.; Zhang, Z.; Fu, Q.; Peng, L.; et al. Repeated growth and bubbling transfer of graphene with millimetre-size single-crystal grains using platinum. Nat. Commun. 2012, 3, 699. [CrossRef]

11. Gao, L.; Ni, G.-X.; Liu, Y.; Liu, B.; Castro Neto, A.H.; Loh, K.P. Face-to-face transfer of wafer-scale graphene films. Nature 2013, 505, 190-194. [CrossRef] [PubMed]

12. Kim, H.; Song, I.; Park, C.; Son, M.; Hong, M.; Kim, Z.; Kim, J.S.; Shin, H.; Baik, J.; Choi, C. Copper-Vapor-Assisted Chemical Vapor Deposition for High-Quality and Metal-Free Single-Layer Graphene on Amorphous $\mathrm{SiO}_{2}$ Substrate. ACS Nano 2013, 7, 6575-6582. [CrossRef] [PubMed]

13. Ismach, A.; Druzgalski, C.; Penwell, S.; Schwartzberg, A.; Zheng, M.; Javey, A.; Bokor, J.; Zhang, Y. Direct chemical vapor deposition of graphene on dielectric surfaces. Nano Lett. 2010, 10, 1542-1548. [CrossRef] [PubMed]

14. Kaplas, T.; Sharma, D.; Svirko, Y. Few-layer graphene synthesis on a dielectric substrate. Carbon 2012, 50, 1503-1509. [CrossRef]

15. Marchena, M.; Janner, D.; Chen, T.L.; Finazzi, V.; Pruneri, V. Low temperature direct growth of graphene patterns on flexible glass substrates catalysed by a sacrificial ultrathin Ni film. Opt. Mat. Express 2016, 6, 2487-2507. [CrossRef]

16. Alexeev, A.M.; Barnes, M.D.; Nagareddy, V.K.; Craciun, M.F.; Wright, C.D. A simple process for the fabrication of large-area CVD graphene based devices via selective in situ functionalization and patterning. 2D Mater. 2016, 4, 011010. [CrossRef]

17. Lanza, M.; Bayerl, A.; Gao, T.; Porti, M.; Nafria, M.; Jing, G.Y.; Zhang, Y.F.; Liu, Z.F.; Duan, H.L. Graphene-coated atomic force microscope tips for reliable nanoscale electrical characterization. Adv. Mater. 2013, 25, 1440-1444. [CrossRef]

18. Klemenz, A.; Pastewka, L.; Balakrishna, S.G.; Caron, A.; Bennewitz, R.; Moseler, M. Atomic scale mechanisms of friction reduction and wear protection by graphene. Nano Lett. 2014, 14, 7145-7152. [CrossRef]

19. Cheng, C.E.; Lin, C.Y.; Shan, C.H.; Tsai, S.Y.; Lin, K.W.; Chang, C.S.; Shih-Sen Chien, F. Platinum-graphene counter electrodes for dye-sensitized solar cells. J. Appl. Phys. 2013, 114, 014503. [CrossRef]

20. Park, H.; Zhang, S.; Steinman, A.; Chen, Z.; Lee, H. Graphene prevents neurostimulation-induced platinum dissolution in fractal microelectrodes. 2D Mater. 2019, 6, 035037. [CrossRef]

21. Lucca, B.G.; de Lima, F.; Coltro, W.K.T.; Ferreira, V.S. Electrodeposition of reduced graphene oxide on a Pt electrode and its use as amperometric sensor in microchip electrophoresis. Electrophoresis 2015, 36, 1886-1893. [CrossRef] [PubMed]

22. Molina, J.; Fernández, J.; García, C.; Del Río, A.I.; Bonastre, J.; Cases, F. Electrochemical characterization of electrochemically reduced graphene coatings on platinum. Electrochemical study of dye adsorption. Electrochim. Acta 2015, 166, 54-63. [CrossRef]

23. Gutés, A.; Hsia, B.; Sussman, A.; Mickelson, W.; Zettl, A.; Carraroa, C.; Maboudian, R. Graphene decoration with metal nanoparticles: Towards easy integration for sensing applications. Nanoscale 2012, 4, 438-440. [CrossRef] [PubMed]

24. Huang, J.; Tian, J.; Zhao, Y.; Zhao, S. Ag/Au nanoparticles coated graphene electrochemical sensor for ultrasensitive analysis of carcinoembryonic antigen in clinical immunoassay. Sens. Actuators B Chem. 2015, 206, 570-576. [CrossRef]

25. Shao, Y.; Wang, J.; Wu, H.; Liu, J.; Aksay, I.A.; Lin, Y. Graphene Based Electrochemical Sensors and Biosensors: A Review. Electroanalysis 2010, 22, 1027-1036. [CrossRef]

26. Yuan, W.; Shi, G. Graphene-based gas sensors. J. Mater. Chem. A 2013, 1, 10078-10091. [CrossRef]

27. Pérez-Mas, A.M.; Álvarez, P.; Campos, N.; Gómez, D.; Menéndez, R. Graphene patterning by nanosecond laser ablation: The effect of the substrate interaction with graphene. J. Phys. D. Appl. Phys. 2016, 49, 305301. [CrossRef]

28. Feng, J.; Li, W.; Qian, X.; Qi, J.; Qi, L.; Li, J. Patterning of graphene. Nanoscale 2012, 4, 4883-4899. [CrossRef] [PubMed]

29. Sutter, P.; Sadowski, J.T.; Sutter, E. Graphene on Pt(111): Growth and substrate interaction. Phys. Rev. B 2009, 80, 1-10. [CrossRef] 
30. Kang, B.J.; Mun, J.H.; Hwang, C.Y.; Cho, B.J. Monolayer graphene growth on sputtered thin film platinum. J. Appl. Phys. 2009, 106, 104309. [CrossRef]

31. Nam, J.; Kim, D.C.; Yun, H.; Shin, D.H.; Nam, S.; Lee, W.K.; Hwang, J.Y.; Lee, S.W.; Weman, H.; Kim, K.S. Chemical vapor deposition of graphene on platinum: Growth and substrate interaction. Carbon 2017, 111, 733-740. [CrossRef]

32. Firebaugh, S.L.; Jensen, K.F.; Schmidt, M.A. Investigation of high-temperature degradation of platinum thin films with an in situ resistance measurement apparatus. J. Microelectromech. Syst. 1998, 7, 128-135. [CrossRef]

33. Guarnieri, V.; Biazi, L.; Marchiori, R.; Lago, A. Platinum metallization for MEMS application: Focus on coating adhesion for biomedical applications. Biomatter 2014, 4, 2-8. [CrossRef] [PubMed]

34. Madaan, N.; Kanyal, S.S.; Jensen, D.S.; Vail, M.A.; Dadson, A.E.; Engelhard, M.H.; Samha, H.; Linford, M.R. $\mathrm{Al}_{2} \mathrm{O}_{3}$ e-Beam Evaporated onto Silicon (100)/SiO ${ }_{2}$, by XPS. Surf. Sci. Spectra 2013, 20, 43-48. [CrossRef]

35. Tarabella, G.; Balducci, A.G.; Coppedè, N.; Marasso, S.; D'Angelo, P.; Barbieri, S.; Cocuzza, M.; Colombo, P.; Sonvico, F.; Mosca, R.; et al. Liposome sensing and monitoring by organic electrochemical transistors integrated in microfluidics. Biochim. Biophys. Acta, Gen. Subj. 2013, 1830, 4374-4380. [CrossRef] [PubMed]

36. Marasso, S.L.; Tommasi, A.; Perrone, D.; Cocuzza, M.; Mosca, R.; Villani, M.; Zappettini, A.; Calestani, D. A new method to integrate $\mathrm{ZnO}$ nano- tetrapods on MEMS micro-hotplates for large scale gas sensor production. Nanotechnology 2016, 27, 1-7. [CrossRef] [PubMed]

37. Tommasi, A.; Cocuzza, M.; Perrone, D.; Pirri, C.; Mosca, R.; Villani, M.; Delmonte, N.; Zappettini, A.; Calestani, D.; Marasso, S. Modeling, Fabrication and Testing of a Customizable Micromachined Hotplate for Sensor Applications. Sensors 2016, 17, 62. [CrossRef] [PubMed]

38. Wang, Y.; Ni, Z.; Yu, T.; Shen, Z.X.; Wang, H.; Wu, Y.; Chen, W.; Thye, A.; Wee, S. Raman Studies of Monolayer Graphene: The Substrate Effect. J. Phys. Chem. C 2008, 112, 10637-10640. [CrossRef]

39. Hawaldar, R.; Merino, P.; Correia, M.R.; Bdikin, I.; Grácio, J.; Méndez, J.; Martín-Gago, J.A.; Singh, M.K. Large-area high-throughput synthesis of monolayer graphene sheet by Hot filament thermal chemical vapor deposition. Sci. Rep. 2012, 2, 2-10. [CrossRef]

40. Ferrari, A.C.; Basko, D.M. Raman spectroscopy as a versatile tool for studying the properties of graphene. Nat. Nanotechnol. 2013, 8, 235-246. [CrossRef]

41. Park, H.J.; Meyer, J.; Roth, S.; Skákalová, V. Growth and properties of few-layer graphene prepared by chemical vapor deposition. Carbon 2010, 48, 1088-1094. [CrossRef]

42. Jerng, S.-K.; Seong Yu, D.; Hong Lee, J.; Kim, C.; Yoon, S.; Chun, S.-H. Graphitic carbon growth on crystalline and amorphous oxide substrates using molecular beam epitaxy. Nanoscale Res. Lett. 2011, 6, 565. [CrossRef] [PubMed]

(C) 2019 by the authors. Licensee MDPI, Basel, Switzerland. This article is an open access article distributed under the terms and conditions of the Creative Commons Attribution (CC BY) license (http://creativecommons.org/licenses/by/4.0/). 